that afflicts humanity, yet we feel compelled to say that we have little hope of the cure of tuberculosis by this means." We agree with the last statement most fully, and undoubtedly the question of serum-therapy could not be more vigorously or more righteously disposed of. Our leading manufacturers are supplying quantities of serum to those who believe in the use of immunized serums in general, but I am glad to know that one firm in Detroit, Mich., Messrs. Parke, Davis $\&$ Co., are using the facilities their magnificent plant affords to provide free of expense to physicians for experiment, normal non-immunized serum. At the meeting of the American Medical Association in Philadelphia, I was, I believe, the first in the country to urge the value of normal non-immunized, horse blood serum es a natural antitoxin, not only in the treatment of tuberculosis but of diphtheria and scarlet fever, and in wasting disease in general. For many years I have contributed articles on the climatic treatment of tuberculosis in Colorado and New Mexico, where I have myself witnessed many recoveries, but in recent years I have believed that while climatic treatment is the most desirable, blood serum is a powerful means of cure. The serum with the climatic treatment is my ideal. I have been working for some time to create an interest in what I call the goat cure. A resort where healthy outdoor exercise can be indulged in, either at the seashore or in the Maine or Adirondack forests, or west of the Mississippi, and goat's milk to drink, goat's flesh to eat, and goat's blood either for rectal injection or for drinking, and finally, goat's blood (normal) serum injected subcutaneously and, in some urgent cases, by transfusion. It is along these lines I am working and planning, and I believe that time will demonstrate that this method of cure is worthy of general approval. I have already contributed several papers on this subject, and have others in mind to contribute as soon as possible.

Westboro, Mass.

\section{SPECIFIC ACTION OF AIR IN CONSUMPTION.}

BY W. H. WEAVER, M.D.

PROFESSOR OF RHINOLOGY AND LARYNGOLOGY, CHICAGO EYE, EAR, NOSE AND THROAT COLLEGE.

CHICAGO.

Aerotherapeutics in consumption is not a new treatment, although it has had a varied application. Forcibly holding a full breath with the glottis closed was recommended by so ancient an authority as Hippocrates with the idea that it "opened out the channels of breathing." Galen declared that it "opened out the internal cavities." They were positive, however, that it was the proper treatment for consumption. Their explanation for the practice was based upon the antiquated notion that by this pressure of the muscles air was conveyed through all the arteries of the frame. The most reasonable explanation would be that during the compression of a distended chest, with the glottis closed, air finds its way forcibly into little-used, collapsed or plugged-up alveoli, aerating them more perfectly than in ordinary breathing. Much has been written on the subject of climate and aerotherapeutics, chest development and kindred subjects. Inhalations, full breathing and prolonged expirations to increase the tension, chest exercises, and gymnastic exercises are recommended with great benefit, and all the most successful efforts of physicians against the disease are attained in this line. All are efforts in the right direction, but without sufficient philosophic basis to give a uniform system and uniform results.

It will be shown that if air can be kept in the aircells, those cells can not become tubercular, as tuberculosis always involves the infiltration of the alveolar wall and the plugging of the cell. If air can thus prevent the tubercular process, or cure it when once begun, then air is the specific for this disease. That this specific action of air against the miliary tubercular inflammation has been amply demonstrated, there can be but little doubt. The well-known and successful treatment of tuberoular peritonitis involves only one more important point besides the action of air, and that is drainage, which precedes the admission of air to the peritoneum. The tubercle lies in the superficial layers of the peritoneal membrane, and there is no mixed infection, no suppuration to prevent the action of air on a portion, at least, of the membrane and its tubercles. In tubercular ulceration of the larynx, however, we have the destructive processes of mixed infection infiltrating the deep tissues beyond the reach of air.

At the Medical Congress at Rome there were reported 253 cases of tubercular peritonitis operated on, with 85.4 per cent. of recoveries. It was also pointed out that the failures resulted from the serious complications, which of necessity must result fatally. Roersch's statistics make the percentage somewhat less. Of 358 cases, 253 cases, or 70 per cent., were discharged as cured. This large percentage of cures would almost compel us to acknowledge the specific action of air.

Seganti performs "a pneumatic lavage" with a couple of canulas, drawing out the ascitic fluid and admitting air to the peritoneal sac with success.

Although the miliary tubercle is a new growth, it is not stable, and entirely disappears under proper conditions. These conditions are aseptic drainage and the action of air. I am aware that there are other theories which do not recognize these two points as essential in the care of peritoneal tuberculosis, but I consider them based on unimportant facts, and in the analysis of the treatment those two points are always present and are essential. Now, if these two essentials can be applied in the treatment of pulmonary tuber. culosis, we may hope to get similar results.

Asthma is never present in consumption. Attacks of it may occur in acute descending bronchitis, and this condition is often present in the first stage. Emphysema and asthma are notoriously antagonistic to the development of tuberculosis in the lung. Postmortem examinations of chronic asthmatics frequently show the remains of an old tubercular focus-the consequent alveolar distension due to the asthma curing the tubercular disease, or at least rendering it dormant. Air has been brought into direct contact with the tubercular alveolar wall by the emphysematous tendency of asthma.

It has been long known that pulmonary hemorrhage in tubercular phthisis is usually followed by improvement, and the prognosis in the same class of cases is usually very good as to length of life. It seems to me that the proper explanation for this is that the hemorrhage so reduces the congestion of the cell walls that air is more effectually drawn into the alveoli by ordinary breathing, when its beneficial action can be exerted on the inflammation, for a time at least.

Regarding etiology, I believe tubercular phthisis is a disease of inactivity in the majority of cases, 
inactivity or non-use of certain areas of lung tissue, due probably to the weight of the arms and shoulders on the upper chest, together with an insufficient amount of physical activity to aerate the whole lung. Malformation of the chest might be mentioned, but that could be overcome by physical activity and development. Certain alveoli in this area of least activity become congested or entirely occluded by catarrhal products. Soon the ever-present tubercle bacillus enters upon the scene of action and determines the character of the inflammation, until the germs of suppuration assist in the work of destruction.

Hanau states that the apex of the lungs becomes the seat of the tubercular infiltration as the direct result of insufficient ventilation. This explanation is generally received as true, but it has not been studied or considered as a basis for therapeutics.

The existence of the miliary tubercle is not a bar to recovery in peritoneal tuberculosis, and their appearance in lung tissue should be no greater obstacle. Just how aseptic drainage and aeration bring about the favorable results can only be conjectured. Necessarily germs and their toxins are carried out with the exudate, circulation is facilitated and stimulated, nutrition improved, phagocytosis encouruged, and possibly antitoxins formed which aid in restoring health to the inflamed tissues.

Aseptic drainage and ventilation of the alveolus are possible from the elastic nature of the lung parenchyma, and as long as the cell wall is intact air may be forced into it, distending it, and gradually forcing out the gelatinous and albuminous plug with every expiratory effort, or contraction on the confined air behind the plug. That our efforts are successful may be known from the general improvement of the patient, the diminishing area of dulness, the smaller amount of expectoration, the longer wind power and slower pulse of the patient. The increased lung capacity and relief from the shortness of breath is often immediate and surprising. It will not be sufficient to simply have the patient sit out of doors and breathe the outside air, or walk and take gentle exercise, or even pulmonary gymnastics and full breathing, all of which are good. In that treatment we recognize only that air is a good thing, and in some mysterious way improves the general nutrition and condition of the patient. But now base the treatment on the specific action of air on the tubercle, and it will be conceded that the air must be brought into direct contact with it, and any treatment or method which does not recognize that fact and force the air into the alveoli, will fail to give the certain results expected from a specific. The method I use was described in an article which appeared in the JouRnal of THE AMERICAN MEDICAL Association, May 4, 1895̃, entitled "Forcible Alveolar Expansion in the Treatment of Consumption." I direct the patient to take as full an inspiration as possible, then closing the glottis and bearing down just as if straining at stool for a few seconds, so as to increase the tension of the air in the upper chest. In performing the act in that manner the greater effort is expended in the muscles of the abdomen, and consequently the air is forced upward.

A method frequently recommended, of blowing through a small tube in order to increase depth of the respirations, defeats its own purpose, because in the effort of blowing, the expiratory muscles of the chest are brought more strongly into action, compressing equally over the chest, but not in any particular direc. tion, the air being driven out without any alveolar expansion.

The exercise should be practiced frequently so as to keep up a constant effect in the infiltrated area. Five to fifteen minutes every two hours during the waking hours, and frequently at night if awake and coughing. The effect is increased if during the holding of the breath the lower chest is compressed with the hands, which also lifts the weight of the arms and shoulders off the chest. It is not the length of time the breath is held, but the tension developed in a few seconds, from which the benefit is derived. This is the simplest and easiest manner of holding the breath, and may be practiced without attracting the attention of anyone; still, it is difficult for some patients to learn and establish the habit so as to continue it regularly. It will require some practice in order to get the best results, but an ambitious patient will usually pick it up very quickly.

In order to increase the interest in the treatment, a nebulizer should be given the patient, and the importance of getting the antiseptic nebula well down into the air-cells by the method described above impressed upon him. The nebula will, of course, assist in relieving the bronchial catarrh so common and troublesome. Massage of the chest by manual compression of the lower chest during the holding of the fuil breath, I often practice as part of an office treatment with a multinebulizer. The tension developed in the lung should not be too high at first, but may be quite rapidly increased, especially when there is no pain or hemoptysis. Neither pain nor hemoptysis are contraindications to the treatment, as they both disappear in a short time. I usually practice the massage at the office every day, or every other day. If the glottis is not closed in this act of holding the breath, air is drawn into the lungs, but there is no tension developed, and it is simply an inspiratory exercise, and fails to accomplish the end desired, because it does not forcibly dilate the alveoli. Active exercise producing rapid respiratory efforts in cases not too far advanced will go far toward carrying the air into the alveoli.

The immediate results will be an increased amount of oxygen in the blood, a strengthened heart's action and facilitated expectoration. Thorough inflation of the chest always gives great relief from shortness of breath. The effect of the alternate expansion and contraction of the chest is to force out the contents of the alveoli into the bronchioles, then into the larger tubes until they are expectorated. This is drainage and makes ventilation possible; each alveolus thus ventilated is soon restored to health by the action of the air on the miliary tubercle in the cell wall. The area of consolidation is gradually reduced, and infiltration clears up. Expectoration is gradually reduced in amount. The general improvement and well-feeling of the patient is soon very manifest.

I am not sure that the treatment is of much benefit in rapid cases, although it does make breathing much easier, and facilitates expectoration. However, if it be applied energetically with the use of oxygen gas, good results may be obtained. Over-distension of the alveolus is hardly possible, and emphysema no more serious than might occur from violent straining at stuol in constipation, or from the expulsive pains of child-birth. I do not know of any serious contraindications to the treatment. One might expect hemorrhage to be increased from the increased activity to 


\begin{tabular}{l|l|l|l|l|l|l|l|l|}
\hline \hline \\
\hline
\end{tabular}

Second stage cases.

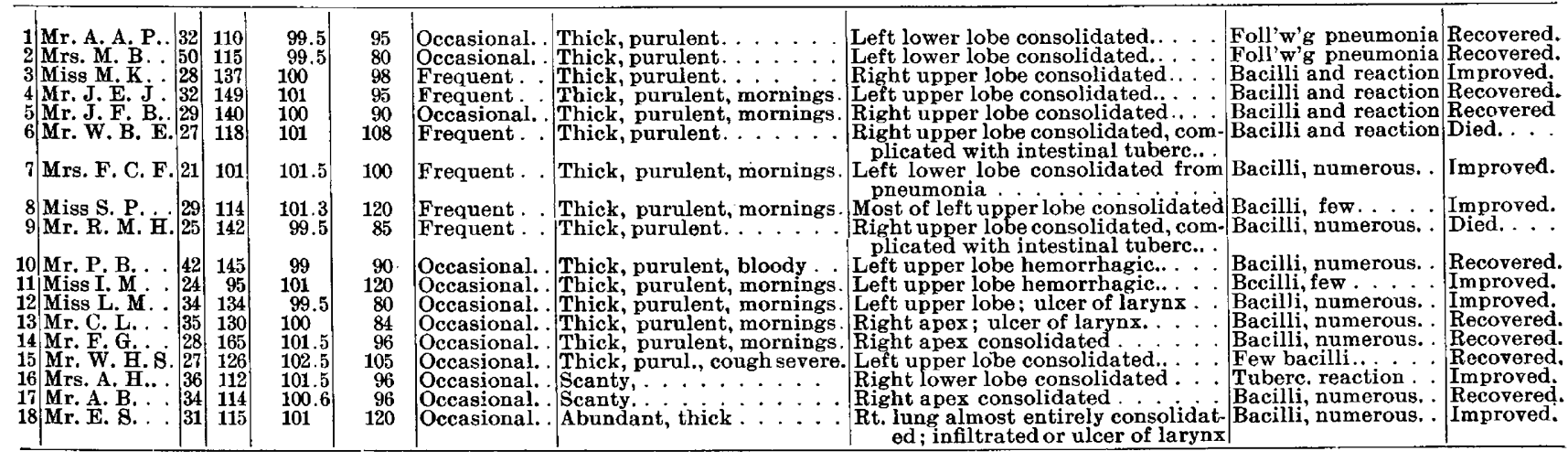

Second Stage Cases.-Dr. Salter's

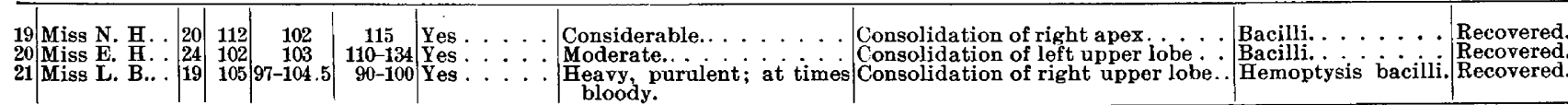

Third Stage.

\begin{tabular}{|c|c|c|c|c|c|c|c|c|c|c|c|}
\hline$\dot{0}$ & Case. & 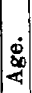 & $\left|\begin{array}{c}\overrightarrow{2} \\
.00 \\
0 \\
0\end{array}\right|$ & Temp. & Pulse. & $\begin{array}{l}\text { Night } \\
\text { sweats. }\end{array}$ & Expectoration. & $\begin{array}{l}\text { Complica- } \\
\text { tion. }\end{array}$ & Examination of lungs. & Basis of diagnosis. & Result. \\
\hline 1 & Miss J. S. G.. & 45 & 108 & 99.7 & 96 & Occasional & Abundant and purulent & & Consolidation of left & Numerous bacilli. & Improved. \\
\hline 2 & Miss M.McF. & 19 & 112 & $97-101.5$ & 130 & Frequent.. & Considerable. & Prof'nd ane- & Cavity in left upper lobe. & Few bacilli & Improved tem. \\
\hline & $\begin{array}{l}\text { Mr. H. C }: \\
\text { Mr. N. D : }: \text {. }\end{array}$ & $\begin{array}{l}20 \\
27 \\
45\end{array}$ & $\begin{array}{l}100 \\
116 \\
135\end{array}$ & $\mid \begin{array}{c}97-105 \\
102 \\
103.4\end{array}$ & $\begin{array}{l}116 \\
136 \\
110\end{array}$ & $\begin{array}{l}\text { Frequent.. } \\
\text { Frequent.. } \\
\text { Frequent.. }\end{array}$ & $\begin{array}{l}\text { Thick, heavy, purulent. } \\
\text { Thick, heavy, purulent. } \\
\text { Thick, heavy, purulent. }\end{array}$ & Extensive ul- & $\begin{array}{l}\text { Cavity in right upper lobe. } \\
\text { Cavity in right upper lobe } \\
\text { Cavity in left upper lobe, }\end{array}$ & $\begin{array}{l}\text { Numerous bacilli. } \\
\text { Numerous bacilli. } \\
\text { Numerous bacilli. }\end{array}$ & $\begin{array}{l}\text { Died. } \\
\text { Died. } \\
\text { Improved; died. }\end{array}$ \\
\hline & $\begin{array}{l}\text { Mr. A. P. . . } \\
\text { Mr. C. C. . }\end{array}$ & 25 & $\begin{array}{r}98 \\
105\end{array}$ & $\begin{array}{l}103.5 \\
101\end{array}$ & $\begin{array}{l}136 \\
110\end{array}$ & $\begin{array}{l}\text { Profuse . } \\
\text { Occasional }\end{array}$ & $\begin{array}{l}\text { Thick, heavy, purulent. } \\
\text { Thick, heavy, purulent. }\end{array}$ & Extensive ui- & $\begin{array}{l}\text { Cavities in both up. Iobes. } \\
\text { Cavity in left lung. }\end{array}$ & $\begin{array}{l}\text { Numerous bacilli. } \\
\text { Numerous bacilli. }\end{array}$ & $\begin{array}{l}\text { Improved; died. } \\
\text { Improved; died. }\end{array}$ \\
\hline & Mr. T. N. & 19 & $\begin{array}{r}110 \\
94\end{array}$ & $\begin{array}{r}99 \\
103\end{array}$ & $\begin{array}{c}115 \\
120-130\end{array}$ & $\begin{array}{l}\text { Occasional } \\
\text { Frequent.. }\end{array}$ & $\begin{array}{l}\text { Thick, heavy, purulent. } \\
\text { Abundant. . . . . }\end{array}$ & $\because \ldots$ & $\begin{array}{l}\text { Cavity in left lung. . } \\
\text { Cavity in left lung. }\end{array}$ & $\begin{array}{l}\text { Numerous bacilli. } \\
\text { Numerous bacilli. }\end{array}$ & $\begin{array}{l}\text { Improved; died. } \\
\text { Died. }\end{array}$ \\
\hline
\end{tabular}

which the lung is put, but, as a matter of fact, I have / rapid sort of phthisis, it is hardly possible for the dishad the very best results in hemorrhagic cases, in some ease to make any progress in the lung tissues if the cases the hemorrhages disappearing in a few days, never treatment is carried out conscientiously. And I beto return. The existence of cavities seems to be no lieve that every uncomplicated case taken short of the contraindication, although necessarily that class of stage of ulceration and mixed infection, will be found cases will not respond to the treatment very rapidly. curable. As supplementary measures in the managePleurisy, if quite general, may be aggravated by the ment of the disease are also very necessary, some im. extensive chest movements and the pain be consider- portant ones may be mentioned: the recumbent posiable for a time, until the tubercular inflammation tion during high fever in the afternoon; light meals under the pleura has subsided. In one of my early during fever. To overcome the muscular atrophy cases there were friction murmurs over the whole about the chest, any gymnastic exercises will be of chest, and the exercise was most painful for several benefit provided they do not fatigue. Appropriate months, but by persisting in it improvement came and medication should be directed toward improving the ultimately complete recovery.

The method I have advocated might be termed "auto-pneumatic differentiation." It has the advantage that the patient is continually under its influence while practicing it. Tubercle bacilli can never attack normal lung tissue in active use, consequently I promise my patients that so long as they make active and forcible use of their lungs, there is not the slightest danger of relapse or contracting the disease anew. Unless a digestion, but the routine tonics may as well be omitted if they do not positively improve the condition of the stomach. The rapidity of improvement will depend greatly on the extent of the consolidation and the inroads the disease has made in the constitution of the patient, as well as the zeal with which the patient carries out the treatment.

With regard to climate, a patient certainly stands a better chance of recovery at home, with the comforts case is far advanced in the third stage, or is of the of a home, if he has correct treatment, than if he went 
to another climate, depending upon the climate alone for his cure, as is usually the case. Altitude has cured a large number of cases; the cure, however, rather coming from the increased activity to which the lung is put as one goes to a higher altitude. That benefit is doubtful if the patient remains indoors in a hotel, or is unable to be out of doors. When all first-stage cases and over half of the second-stage cases can be cured at home, there is little to be gained in sending them to another climate without treatment.

It will soon be admitted that tuberculosis of the lungs in the early stages is the most curable of any of the chronic diseases, and in the last stage it is about the most hopeless of any, consequently we must consider the early diagnosis of the disease the most important point in its management next to correct treatment. It is simply criminal to make a false diagnosis and waste time with remedies which do little but interfere with digestion, until the case has advanced to the last stages, and then advise to change climate.

Of the 16 cases reported in my first paper, 15 were cured, and one died of pneumonia, Nine were firststage cases and 7 were second-stage cases. Since that time 3 of the 15 have died-one of consumption de. veloped the following winter from severe exposure, one of acute meningitis, and one from typhoid fever. The remainder are all in good health. Since that report I have treated 34 cases on the basis of the specific action of air, with equally good results in the same classes, although a portion of the cases coming to me have been of the more advanced and complicated sort. Included in this report are three firststage cases and three second-stage cases, reported by my friend, Dr. Allen Salter of Lena, Ill., having practiced the same line of treatment.

Ten first-stage cases were all cured; 21 second. stage cases, 12 were cured, 7 improved and 2 died; 9 third-stage cases, 8 died, some of whom improved temporarily, one being greatly improved for over a year, since which time I have had no report.

Summarizing all the 56 cases we have: 19 first-stage cases cured; 28 second-stage cases, 16 cured, 7 improved, 3 died; in 9 third-stage cases, no cures, 6 improved temporarily. Leaving out of consideration the third-stage cases, for whom we can not hope to do much with any treatment, there are 47 cases, of which 37 were cured, or almost 80 per cent., or 66 per cent. of all the cases.

\section{SOCIETY PROCEEDINGS.}

New Jersey Sanitary Association.

Twenty-fourth Annual Meeting, held at Lakewood, Dec. 9, 1898 .

Dr. W. B. JoHnson of Paterson presented the first paper, entitled

DEFECTIVE VISION IN SCHOOL CHILDREN,

It was not the purpose of the paper to prove by a series of statistics the presence of defective vision in school children and that these are the result of the unsanitary condition of school buildings, or the methods which have dominated our educational system from its inception. A change is now neces sary, not only in the construction of buildings, but also in educational systeme. Over a quarter of a million children have been examined by various observers, showing a high percentage of increase in these troubles and especially in the more populous centers. We have improper sites and overcrowded buildings. Great benefit, however, has resulted from these examinations by the improved sanitary conditions and methods. In future this will be still greater. Defective vision is the re sult of ocular conditions affecting the refraction of the eye caused by structural changes in the eyeball, which is the for- mative stage when these tissues are most susceptible of altera. tion in their contour, and accompanying errors of refraction are the result of continued visual effort overtaxing the muscles and tunics of the eye. Infants have, as a normal ocular condition, a hypermetropia or far sight, almost invariably, and it has been shown that the ball undergoes during school life a change and lengthening of the optic axis. Hence we have emmetropia or the normal condition in childhood, and finally, in many cases developing progressive myopia or some form of simple or compound astigmatism. These changes progress during the natural increase of the eye while the structure is still yielding. This is encouraged by the hyperemia of the globe produced by extra visual effort at this period. If this is regular and progressive it only results in myopia or lengthening of the optic axis. If irregular, astigmatism is produced. What can be done for the relief and prevention of these defects is now the question. Public sentiment should be educated to a reform. The State Board of Education and other bodies have interested themselves and furnished drawings of school buildings, for future benefit in this direction. Many ophthalmologists have formulated plans for this purpose, and circulars for the examination of the eyes of school children have been presented both by municipalities and independent observers. The dissemination of the knowledge thus obtained has resulted in many valuable plans for proper sites for school houses, dimen. sions, arrangements of seats, desks, etc., so that there would be good light, ample capacity, heating and ventilation. It is the hope and belief that in the near future schools will be built only under restrictions which will compel compliance with certain forms and rules for sanitary construction. It is essential for the well-being of all students that the present and the future systematic examination of students be continued and universally adopted. All municipalities should unite in this matter. The New York State Board of Health have issued circulars of instruction for this work. Not only should all be examined, but this should be contiuued from grade to grade to learn whether there is a continued advance in the errore in each case. Errors of refraction should be corrected by glasses, diseased conditions treated, etc. Thus we would have a minimum amount of danger or any increase of ocular defecte prevented. The most acceptable method of procedure is to have all students immediately examined by the family physician and when necessary referred to a competent ophthalmologist. When the eye is reddened or we have discharges, the student should not resume work until a medical certificate is given that it is fully proper, and that there is no danger of infection of others. Blank forms of notification should be prepared for the use of teachers and physicians. In all instances there should be a preliminary examination prior to the entrance of a pupil, both physical and ocular. About one-fifth of the population are destined to pass at least one-third of their natural lives, twothirds of the working hours, at sthool. Hence the importance of knowing the physical adabtability of each for the work before they are admitted. Scientific advances will soon necessitate the assignment of a student with such defects to a privileged class, where by selective atudies, we may enable him to acquire a knowledge commensurate with his educational qualifications, and thus he will be given only that work which he is able to perform, not being advanced till he can do it with safety, nor do work which is more than his strength will allow. One curriculum is not suitable for all, or they will be overtaxed. Teaching should be didactic, with every means to enable the pupil to use the eyes at the distance of the blackboard, thus resting them from close application at the desk. Home work must be lessened, for this is often as bad as at school. A physician should be employed to superintend and inspect the buildings as to heating, lighting, ventilation, cleanliness, etc. There should be an instructor in hygiene for teachers and pupils. This plan was first tried in Germany and was found a success. In the United States there have been only spasmodic efforts in this line. General legislation must come to our aid and make these plans compulsory and thus ensure scientific protection for everyone. Our great advance as a country has been due to the enlightenment of our people. The educational standard has been advanced, and it is of vital importance that attention should be given to every detail in school work that can promote the mental and physical good and prevent degeneration in either of these. Unless the present generation is to nurture a race of mental giants in pigmy forms, steps must be taken at once in the line of preventing diseased conditions or any chance of any character in the children of our public schools.

Dr. G. T. Werch of Passaic-We will have to demonetrate over and over again the evils attending upon unsanitary and inefficient building sites for our schools. We shall have to declaim again and again against badly constructed and illy 